Pacific Journal of Mathematics

THE LACK OF SELF-ADJOINTNESS IN THREE-POINT 


\title{
THE LACK OF SELF-ADJOINTNESS IN THREE-POINT BOUNDARY VALUE PROBLEMS
}

\author{
J. W. NeUberger
}

Suppose that $a<c<b, C_{[a, b]}$ is the set of all real-valued continuous functions on $[a, b]$, each of $p$ and $q$ is in $C_{[a, b]}$, $p(x)>0$ for all $x$ in $[a, b]$ and each of $P, Q$ and $S$ is a real $2 \times 2$ matrix. The assumption is made that the only member $f$ of $C_{[a, b]}$ so that $\left(p f^{\prime}\right)^{\prime}-q f=0$ and

(4) $\quad P\left[\begin{array}{l}f(a) \\ p(a) f^{\prime}(a)\end{array}\right]+Q\left[\begin{array}{l}f(c) \\ p(c) f^{\prime}(c)\end{array}\right]+S\left[\begin{array}{l}f(b) \\ p(b) f^{\prime}(b)\end{array}\right]=\left[\begin{array}{l}0 \\ 0\end{array}\right]$

is the zero function. It follows that there is a real-valued continuous function $K_{12}$ on $[a, b] \times[a, b]$ such that if $g$ is in $C_{[a, b]}$, then the only element $f$ of $C_{[a, b]}$ so that $\left(p f^{\prime}\right)^{\prime}-q f=g$ and $(\Delta)$ holds is given by

$$
f(x)=\int_{a}^{b} K_{12}(x, t) g(t) d t \quad \text { for all } x \text { in }[a, b] .
$$

In this note it is shown that if in addition it is specified that $Q$ is not the zero $2 \times 2$ matrix, then $K_{12}$ is not symmetric, i.e., it is not true that $K_{12}(x, t)=K_{12}(t, x)$ for all $x, t$ in $[a, b]$.

The union of $(a, c)$ and $(c, b)$ is denoted by $R$. The symbol $j$ denotes the identity function on $[a, b]$, i.e., $j(x)=x$ for all $x$ in $[a, b]$. If $V$ is a function from $[a, b] \times[a, b]$ and $x$ is in $[a, b]$, then $V(j, x)$ is the function $h$ such that $h(t)=V(t, x)$ for all $t$ in $[a, b]$. If each of $f$ and $\left(p f^{\prime}\right)^{\prime}-q f$ is in $C_{[a, b]}$, then $\left(p f^{\prime}\right)^{\prime}-q f$ is denoted by $L f$.

Given an element $g$ of $C_{[a, b]}$, one has the problem of determining a function $f$ so that

$$
\left\{\begin{array}{l}
L f=g \text { and } \\
(\Delta) \text { holds }
\end{array}\right.
$$

Denote $\left[\begin{array}{l}0 \\ \int_{a}^{t} 1 / p \\ \int_{a}^{t} q\end{array}\right]$ by $F(t)$ and $\left[\begin{array}{c}0 \\ \int_{a}^{t} g\end{array}\right]$ by $G(t)$ for all $t$ in $[a, b]$.

Then problem $(*)$ may be reformulated as follows: find a function $Y$ from $[a, b]$ to $E_{2}$ such that

(**) $\quad Y(t)=Y(x)+G(t)-G(x)+\int_{x}^{t} d F \cdot Y$ for all $t, x$ in $[a, b]$ and 


$$
\begin{aligned}
& \int_{a}^{b} d H \cdot Y=N \quad \text { where } \\
& H(x)=\left\{\begin{array}{lll}
0 & \text { if } \quad x=a \\
P & \text { if } \quad a<x \leqq c \\
P+Q & \text { if } c<x<b \\
P+Q+S & \text { if } x=b .
\end{array}\right.
\end{aligned}
$$

The assumption is made for the rest of this paper that only the function $Y$ which is constant at $N$ satisfies (**) if $G$ is constant at $N$. It follows that for each continuous function $G$ from $[a, b]$ to $E_{2},(* *)$ has exactly one solution.

Consider the function $M$ from $[a, b] \times[a, b]$ to the set of $2 \times 2$ matricies which has the following property:

$$
M(t, x)=I+\int_{x}^{t} d F \cdot M(j, x) \text { for all } t, x \text { in }[a, b]
$$

where $I=\left[\begin{array}{ll}1 & 0 \\ 0 & 1\end{array}\right]$. Using Theorem $B$ of [2], one has that the unique solution $Y$ of $(* *)$ is given by

$$
\begin{gathered}
Y(t)=\int_{a}^{b} K(t, j) d G \text { for all } t \text { in }[a, b] \text { where } \\
K(t, x)=\left\{\begin{array}{l}
-\left[\int_{a}^{b} d H \cdot M(j, t)\right]^{-1} \int_{x}^{b} d H \cdot M(j, x)+M(t, x) \text { if } a \leqq x \leqq t \\
-\left[\int_{a}^{b} d H \cdot M(j, t)\right]^{-1} \int_{x}^{b} d H \cdot M(j, x) \text { if } t<x \leqq b .
\end{array}\right.
\end{gathered}
$$

That $\left[\int_{a}^{b} d H \cdot M(j, t)\right]^{-1}$ exists for all $t$ in $[a, b]$ follows from the assumption that was made above.

Some straightforward calculation gives that

$$
K(t, x)=\left\{\begin{array}{l}
M(t, b) U(x) M(b, x)+M(t, x) \text { if } a \leqq x \leqq t \\
M(t, b) U(x) M(b, x) \text { if } t<x \leqq b
\end{array}\right.
$$

where

$$
\begin{aligned}
U(x)=\left[\begin{array}{ll}
u_{11}(x) & u_{12}(x) \\
u_{21}(x) & u_{22}(x)
\end{array}\right]=-\left[\int_{a}^{b} d H \cdot M(j b)\right]^{-1} \int_{x}^{b} d H \cdot(j, b) \\
\text { for all } x \text { in }[a, b] .
\end{aligned}
$$

Note that $Y=\left[\begin{array}{c}f \\ p f^{\prime}\end{array}\right]$ where $f$ is the unique solution to $(*)$. Denote $K$ by $\left[\begin{array}{ll}K_{11} & K_{12} \\ K_{21} & K_{22}\end{array}\right]$. It follows that 


$$
f(t)=\int_{a}^{b} K_{12}(t, j) g d j \text { for all } t \text { in }[\alpha, b] .
$$

THEOREM A. If $Q$ is not the 0-matrix (i.e., (*) is $r$ three-point problem) then it is not true that $K_{12}(t, x)=K_{12}(x, t)$ for all $x$ and $t$ in $R$.

Proof. Denote $M$ by $\left[\begin{array}{ll}A & B \\ C & D\end{array}\right]$. From [2] one has the following identities:

$$
\begin{gathered}
B(t, x)=A(t, b) B(b, x)+B(t, b) D(b, x) \quad \text { if } x \text { and } t \text { are in }[a, b] \\
\quad(\text { since } M(t, b) M(b, x)=M(t, x) \text { for all } t, x \text { in }[a, b]), \\
A(t, x) D(t, x)-B(t, x) C(t, x)=1 \quad \text { (i.e., det } M(t, x)=1), \\
A(t, x)=D(x, t), \\
B(t, x)=-B(x, t), \quad \text { and } \\
C(t, x)=-C(x, t) \text { if } x \text { and } t \text { are in }[a, b] .
\end{gathered}
$$

Note that $L A(j, x)=L B(j, x)=0$ if $x$ is in $[a, b]$.

Suppose that

$$
K_{12}(t, x)=K_{12}(x, t) \text { for all } x \text { and } t \text { in } R .
$$

If $a<x<t<b$, then

$$
\begin{aligned}
K_{12}(t, x)= & {\left[A(t, b) u_{11}(x)+B(t, b) u_{21}(x)\right] B(b, x) } \\
& +\left[A(t, b) u_{12}(x)+B(t, b) u_{22}(x)\right] D(b, x)+B(t, x)
\end{aligned}
$$

and

$$
\begin{aligned}
K_{12}(x, t)= & {\left[A(x, b) u_{11}(t)+B(x, b) u_{21}(t)\right] B(b, t) } \\
& +\left[A(x, b) u_{12}(t)+B(x, b) u_{22}(t)\right] D(b, t) .
\end{aligned}
$$

Using the identities listed above,

$$
\begin{aligned}
A(t, b)[ & \left.-u_{11}(x) B(x, b)+u_{12}(x) A(x, b)-B(x, b)\right] \\
& +B(t, b)\left[-u_{21}(x) B(x, b)+u_{22}(x) A(x, b)+A(x, b)\right] \\
= & A(t, b)\left[u_{12}(t) A(x, b)+u_{22}(t) B(x, b)\right] \\
& -B(t, b)\left[u_{11}(t) A(x, b)+u_{21}(t) B(x, b)\right] .
\end{aligned}
$$

An examination of this expression yields the fact that it remains true if $x$ and $t$ are interchanged or $x$ is set equal to $t$.

Denote by $x$ a number in $R$. Since $u_{11}, u_{11}, u_{22}, u_{22}$ are constant on $(a, c)$ and $(c, b)$ and $A(j, b)$ and $B(j, c)$ are independent solutions $v$ of $L v=0$, it follows that

$$
-u_{11}(x) B(x, b)+u_{12}(x) A(x, b)-B(x, b)=u_{12}(t) A(x, b)+u_{22}(t) B(x, b)
$$


and

$$
\begin{array}{r}
\left.-u_{21}(x) B(x, b)+u_{22}(x) A(x, b)+A(x, b)=-u_{11}(t) A(x, b)-u_{21}(t) B(x, b)\right] \\
\text { for all } x \text { and } t \text { in } R .
\end{array}
$$

Similarly, it follows that

(i) $-u_{11}(x)-1=u_{22}(t)$,

(ii) $u_{12}(x)=u_{12}(t)$,

(iii) $u_{21}(x)=u_{21}(t)$ and

(iv) $u_{22}(x)+1=-u_{11}(t)$ for all $x$ and $t$ in $R$.

(ii) and (iii) imply that $u_{12}$ and $u_{21}$ are constant on $R$. (i) and (iv) give the same information so that only (i) need be considered. Denote $u_{11}(c-)$ by $c_{1}, u_{22}(c-)$ by $c_{2}, u_{11}(c+)$ by $c_{3}$ and $u_{22}(c+)$ by $c_{4}$. Hence (i) gives that $c_{1}+c_{2}=-1, c_{1}+c_{4}=-1, c_{3}+c_{4}=-1$ and $c_{3}+c_{2}=-1$. But these equations imply that $c_{2}=c_{4}$ and $c_{1}=c_{3}$, i.e., that $u_{11}$ and $u_{22}$ are constant on $R$. Hence, $U$ is constant on $R$. If $t$ is in $(a, c)$ and $x$ is in $(c, b)$, then

$$
\left[\int_{a}^{b} d H \cdot M(j, b)\right]^{-1} \int_{t}^{x} d H \cdot M(j, b)=U(x)-U(t)=0
$$

so that

$$
Q M(c, b)=\int_{t}^{x} d H \cdot M(j, b)=0,
$$

i.e., $Q=0$, a contradiction. Hence the theorem is established.

If $n$ is an integer greater than 3 , this theorem can be extended to $n$ point boundary value problems. This is the case in which $H$ is a step function with $n$ discontinuities (with one at $a$ and another at $b$ ). What happens when $H$ has points of change other than discontinuities is not at all clear to this author.

\section{REFERENCES}

1. J. W. Neuberger, Concerning boundary value problems, Pacific J. Math. 10 (1960), $1385-1392$.

2. H. S. Wall, Concerning continuous continued fractions and certain system of Stieltjes integral equations, Rend. Circ. Mat. Palermo II 2 (1953). 73-84.

Received February 1, 1965.

EMORY UNIVERSITY 


\section{PACIFIC JOURNAL OF MATHEMATICS}

H. SAMELSON

Stanford University Stanford, California

R. M. BLUMENTHAL

University of Washington

Seattle, Washington 98105

\section{EDITORS}

\author{
*J. DugundJI \\ University of Southern California \\ Los Angeles, California 90007 \\ RICHARD ARENS \\ University of California \\ Los Angeles, California 90024
}

\section{ASSOCIATE EDITORS}

E. F. BeCKENBACH

B. H. NEUMANN

F. WOLF

K. YosidA

\section{SUPPORTING INSTITUTIONS}

UNIVERSITY OF BRITISH COLUMBIA

CALIFORNIA INSTITUTE OF TECHNOLOGY

UNIVERSITY OF CALIFORNIA

MONTANA STATE UNIVERSITY

UNIVERSITY OF NEVADA

NEW MEXICO STATE UNIVERSITY

OREGON STATE UNIVERSITY

UNIVERSITY OF OREGON

OSAKA UNIVERSITY

UNIVERSITY OF SOUTHERN CALIFORNIA
STANFORD UNIVERSITY

UNIVERSITY OF TOKYO

UNIVERSITY OF UTAH

WASHINGTON STATE UNIVERSITY

UNIVERSITY OF WASHINGTON

AMERICAN MATHEMATICAL SOCIETY CHEVRON RESEARCH CORPORATION TRW SYSTEMS

NAVAL ORDNANCE TEST STATION 


\section{Pacific Journal of Mathematics}

Vol. 18, No. 1

March, 1966

Edward Joseph Barbeau, Semi-algebras that are lower semi-lattices ...... 1

Steven Fredrick Bauman, The Klein group as an automorphism group

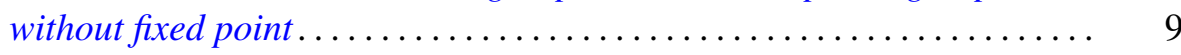

Homer Franklin Bechtell, Jr., Frattini subgroups and $\Phi$-central groups .... 15

Edward Kenneth Blum, A convergent gradient procedure in prehilbert

spaces ............................................

Edward Martin Bolger, The sum of two independent exponential-type random variables ...................................

David Wilson Bressler and A. P. Morse, Images of measurable sets .......

Dennison Robert Brown and J. G. LaTorre, A characterization of uniquely

divisible commutative semigroups........................

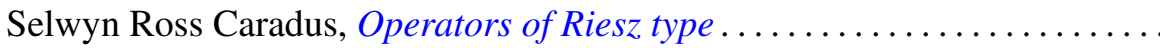

Jeffrey Davis and Isidore Isaac Hirschman, Jr., Toeplitz forms and ultraspherical polynomials ............................

Lorraine L. Foster, On the characteristic roots of the product of certain rational integral matrices of order two ......................

Alfred Gray and S. M. Shah, Asymptotic values of a holomorphic function

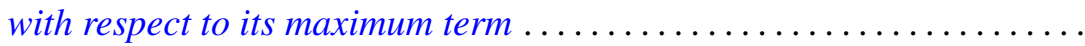

Sidney (Denny) L. Gulick, Commutativity and ideals in the biduals of

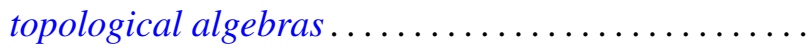

G. J. Kurowski, Further results in the theory of monodiffric functions

Lawrence S. Levy, Commutative rings whose homomorphic images are self-injective .

Calvin T. Long, On real numbers having normality of order $k$....

Bertram Mond, An inequality for operators in a Hilbert space. ...

John William Neuberger, The lack of self-adjointness in three-point boundary value problems ........................

C. A. Persinger, Subsets of $n$-books in $E^{3}$

Oscar S. Rothaus and John Griggs Thompson, A combinatorial problem in the symmetric group ............................... 175

Rodolfo DeSapio, Unknotting spheres via Smale .................. 179

James E. Shockley, On the functional equation

$$
F(m n) F((m, n))=F(m) F(n) f((m, n)) \ldots \ldots \ldots
$$

Kenneth Edward Whipple, Cauchy sequences in Moore spaces ... 